\title{
Aspects of HF radio propagation
}

\author{
E. Michael Warrington ( $\left({ }^{1}\right)$, Alain Bourdillon $\left({ }^{2}\right)$, Eulalia Benito $\left(^{3}\right)$, Cesidio Bianchi $\left({ }^{4}\right)$, \\ Jean-Philippe Monilié $\left({ }^{3}\right)$, Martha Muriuki $\left({ }^{1}\right)$, Marco Pietrella $\left({ }^{4}\right)$, Veronique Rannou $\left({ }^{3}\right)$, \\ Hanna Rothkaehl $\left({ }^{5}\right)$, Stephane Saillant $\left({ }^{3}\right)$, Ozgur Sari $\left({ }^{6}\right)$, Alan J. Stocker $\left({ }^{1}\right)$, Ersin Tulunay $\left({ }^{7}\right)$, \\ Yurnadur Tulunay $\left({ }^{8}\right)$ and Nikolay Y. Zaalov $\left({ }^{1}\right)$ \\ (1) Department of Engineering, University of Leicester, UK \\ ${ }^{2}{ }^{2}$ IETR, Université de Rennes 1, France \\ $\left.{ }^{(}\right)$Electromagnetism and Radar Department, Onera, Palaiseau, France \\ $\left({ }^{4}\right)$ Istituto Nazionale di Geofisica e Vulcanologia, Roma, Italy \\ ${ }^{5}$ ) Space Research Centre PAS 00-716 Warsaw, Poland \\ $\left.{ }^{6}{ }^{6}\right)$ Aselsan A.S., Macunkoy, Ankara, Turkey \\ (') ODTÜ/METU, Department of Electrical and Electronics Engineering, Ankara, Turkey \\ $\left.{ }^{8}\right)$ ODT /METU, Department of Aerospace Engineering, Ankara, Turkey
}

\begin{abstract}
The propagation characteristics of radio signals are important parameters to consider when designing and operating radio systems. From the point of view Working Group 2 of the COST 296 Action, interest lies with effects associated with propagation via the ionosphere of signals within the HF band. Several aspects are covered in this paper:

a) The directions of arrival and times of flight of signals received over a path oriented along the trough have been examined and several types of propagation effects identified. Of particular note, combining the HF observations with satellite measurements has identified the presence of irregularities within the floor of the trough that result in propagation displaced from the great circle direction. An understanding of the propagation effects that result in deviations of the signal path from the great circle direction are of particular relevance to the operation of $\mathrm{HF}$ radiolocation systems.

b) Inclusion of the results from the above mentioned measurements into a propagation model of the northerly ionosphere (i.e. those regions of the ionosphere located poleward of, and including, the mid-latitude trough) and the use of this model to predict the coverage expected from transmitters where the signals impinge on the northerly ionosphere.

c) Development of inversion techniques enabling backscatter ionograms obtained by an HF radar to be used to estimate the ionospheric electron density profile. This development facilitates the operation of over the horizon HF radars by enhancing the frequency management aspects of the systems.

d) Various propagation prediction techniques have been tested against measurements made over the trough path mentioned above, and also over a long-range path between Cyprus and the UK.

e) The effect of changes in the levels of ionospheric disturbances on the operational availability at various data throughput rates has been examined for the trough path mentioned earlier.

The topics covered in this paper are necessarily brief, and the reader is referred to full papers referenced herein on individual aspects.
\end{abstract}

Key words Ionospheric propagation - mid-latitude trough - radiolocation - propagation modelling backscatter sounding

Mailing address: Prof. E. Michael Warrington, Department of Engineering, University of Leicester, Leicester, LE1 7RH, U.K.; e-mail: emw@leicester.ac.uk

\section{Propagation along the mid-latitude trough}

\subsection{Introduction}

For terrestrial HF radio systems, the electron density depletion in the trough region reduces the maximum frequency that can be re- 
flected by the ionosphere along the great circle path (GCP). For long paths, the signal is often received via a ground/sea-scatter mechanism to the side of the GCP (Stocker et al., 2003). For shorter paths, gradients in electron density associated with the trough walls and embedded ionospheric irregularities often result in propagation in which the signal path is well displaced from the great circle direction, with directions of arrival at the receiver offset by up to $100^{\circ}$ (Rogers et al., 1997). Deviations from the great circle direction impact not only on radiolocation systems for which estimates of a transmitter location are obtained by triangulation from a number of receiving sites, but also on any radio communications system in which directional antennas are employed. Furthermore, the Doppler and multi-mode delay spread characteristics of the signal are also affected when propagation is via scatter/reflection from irregularities in or close to the north wall of the trough (Warrington and Stocker, 2003).

Recently, measurements have been made of the direction of arrival (DOA) and amplitude as a function of time of flight (TOF) of HF signals received over two paths oriented along the trough between Uppsala, Sweden (2001 and from August 2006 to January 2008) and Helsinki, Finland (since December 2006) and the University of Leicester's field site near to Leicester (see fig. 1). The first of these periods was close to sunspot maximum, and the second close to sunspot minimum.

\subsection{Characteristic types of propagation along the trough}

Examination of the observations along the trough path from Uppsala and Helsinki has enabled five types of off great circle propagation
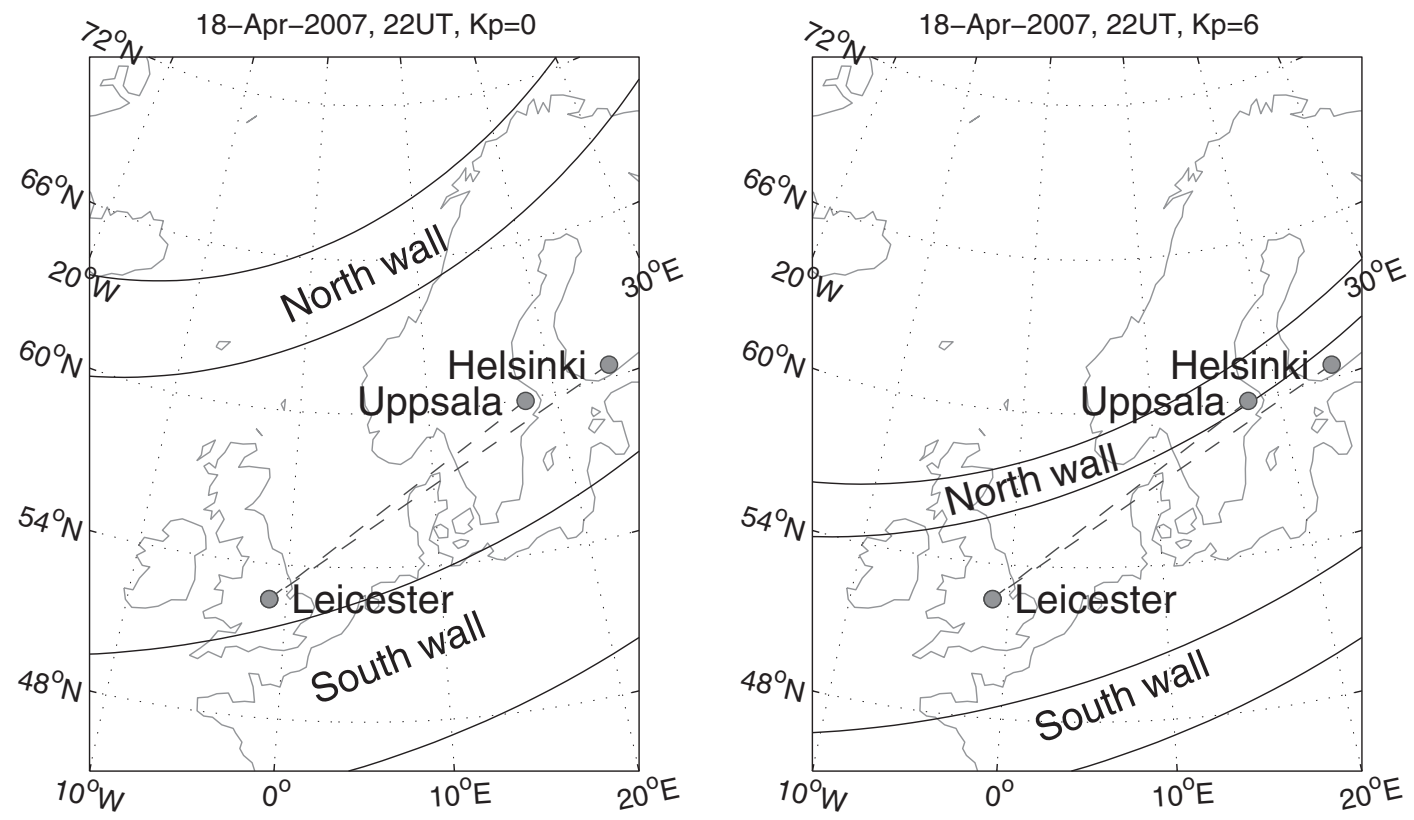

Fig. 1. Maps showing the paths between Uppsala and Leicester and Helsinki and Leicester together with a typical position for the trough, as estimated by the model of Halcrow and Nisbet (1977) for 0000 UT on 11 March 2006 for $\mathrm{Kp}$ values of 0 and 6. The four lines indicate the outer and inner edges of the north and south walls of the trough. 

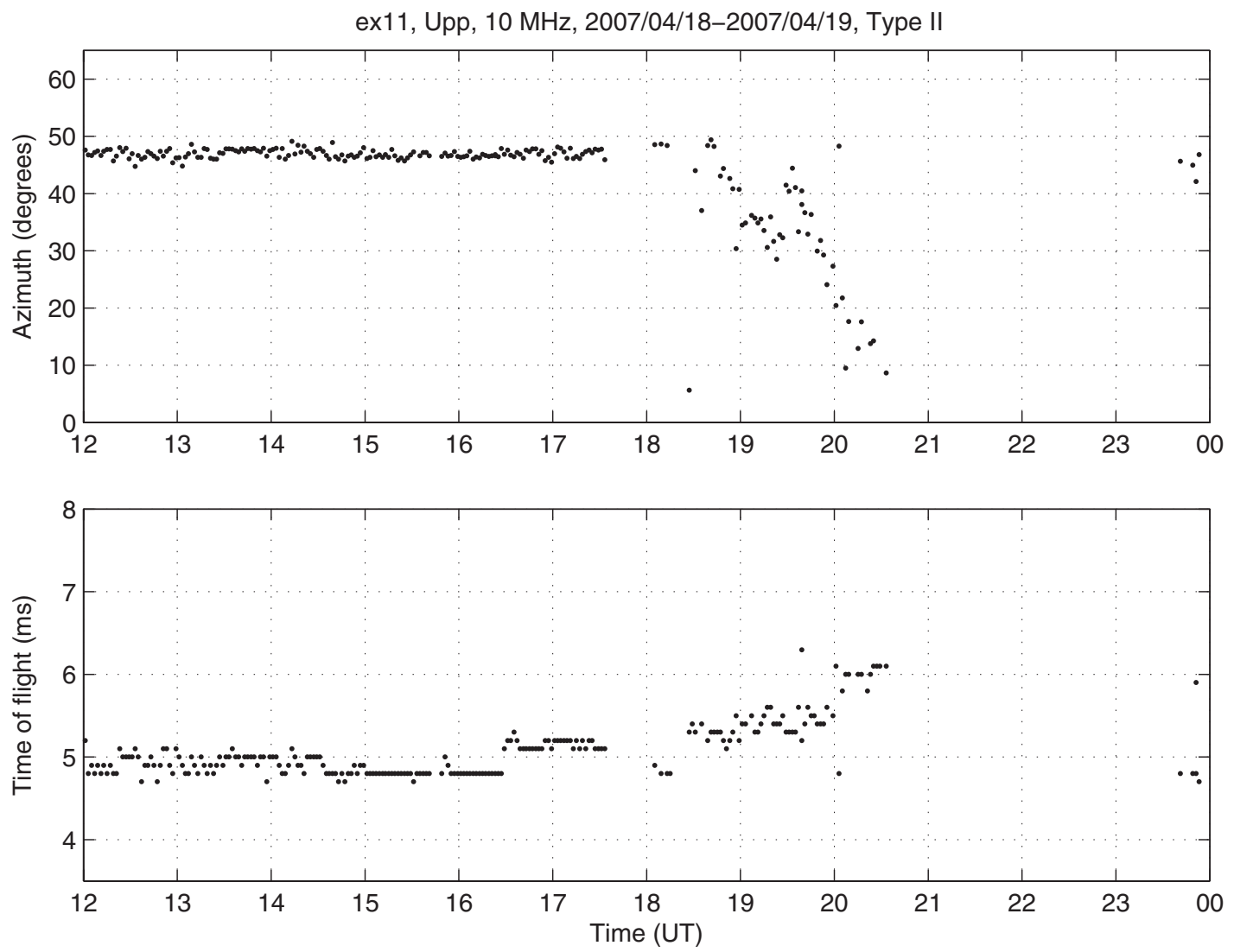

Fig. 2. Type 2 example, azimuth and TOF only.

events to be identified (see Stocker et al. (2009) for full details):

- Type 1: These are characterised at onset by a large sudden increase in time of flight accompanied by a sudden deviation of the bearing to the north. Subsequently, the time of flight decreases over a period of hours while the azimuth either remains fairly constant or returns slowly to close to the great circle direction. Type 1 events were commonly observed, except in the summer, close to solar maximum (2001) (see Siddle et al., 2004a for a number of examples) when they also tended to be longerlived and were observed on a wider range of frequencies. Theoretical considerations indicate that these events are consistent with the signal scattering from irregularities in the poleward wall of the trough or from the auroral region (Siddle et al., 2004b).

- Type 2: The time of flight gradually increases and is accompanied by a gradual deviation of the azimuth to the north (e.g. see the traces for 10 $\mathrm{MHz}$ in fig. 2). The rate of change of time of flight and azimuth tends to be fairly constant until, after a period of up to a few hours, the signal is no longer detected.

- Type 3: The time of flight gradually increases and is accompanied by either a gradual southward (Type 3S) or, less frequently, northward (Type $3 \mathrm{~N}$ ) deviation of the azimuth. After a few hours either the signal is no longer detected or the azimuth slowly returns to the great cir- 
cle direction (this distinguishes Type $3 \mathrm{~N}$ propagation from Type 2).

- Type 4: This type of propagation is characterised by a sudden large increase in the time of flight and a strong deviation to the south (typically the azimuth is around $120^{\circ}$ ). The signal is usually relatively weak, and is consistent with sidescatter from a ground reflection in the vicinity of the Alps.

- Type 5: This type is similar to Type 1 , except that although there is a sudden increase in the time of flight, the signal is deviated to the south instead of the north. Over the following

Type 1
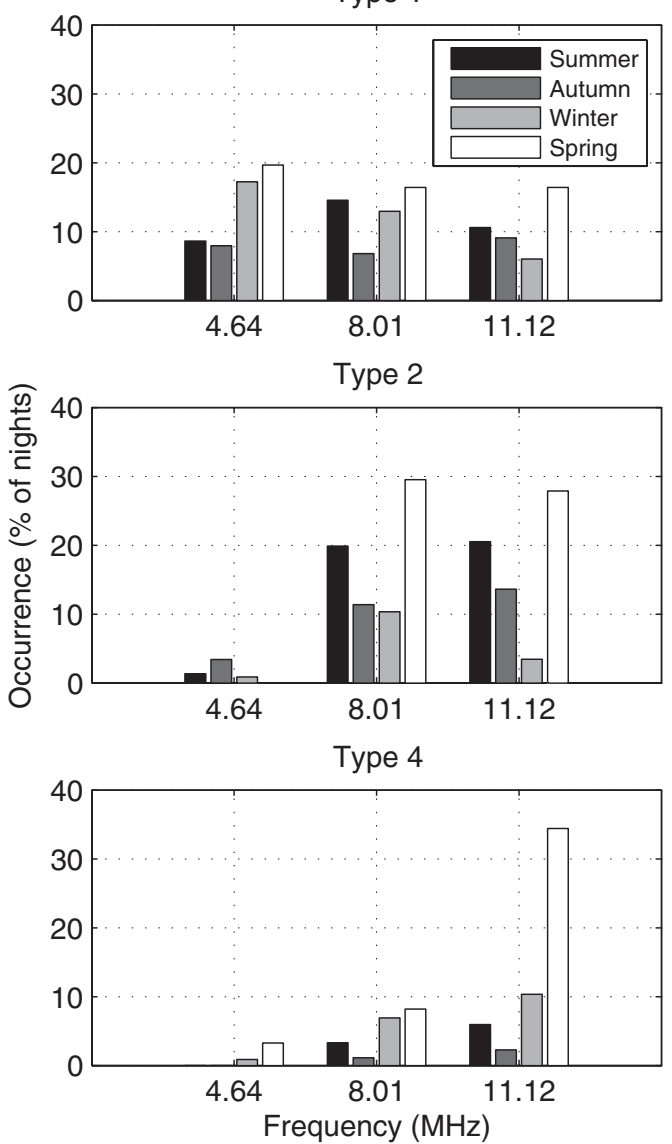

few hours the azimuth usually returns to the great circle direction.

The occurrence (as a percentage of nights of observation) of Types 1,2 , and 4 as a function of season, frequency and $\mathrm{Kp}$ is presented in fig. 3 (Types 3 and 5 are generally rare). The seasons have been defined with spring including all of March and April, summer including May to August, autumn September and October and winter November to February (as in ITU, 1997). Type 1 events are most common in spring with no clear trend with frequency. For 4.64 MHz, this type of propagation is also
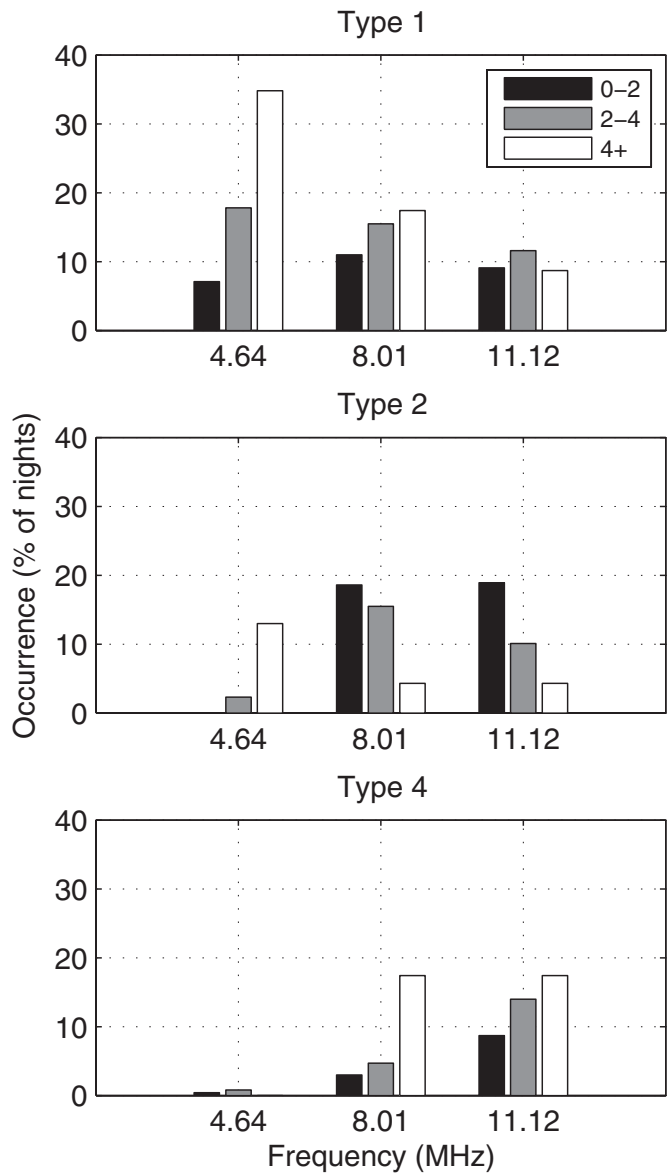

Fig. 3. The percentage occurrence of Types 1, 2, and 4 off great circle propagation (August 2006-September 2007). Left hand panels show variation with season, and the right hand panels the variation with Kp (averaged 1800-0000 UT). 
common in winter, while for most other frequencies it occurs least often in winter. This behaviour may be contrasted with that observed in 2001 (see Siddle et al., 2004a,b) where Type 1 propagation was frequently observed ( 40-70\% of nights depending on frequency) except in summer. Furthermore, the events observed in 2001 tended to consist of larger changes in time of flight and azimuth and to be of longer duration. Type 2 events tend to occur more frequently in spring and, for frequencies in the range $8.01-11.12 \mathrm{MHz}$, in the summer. However, for $6.95 \mathrm{MHz}$, there is little other seasonal variation, while at 4.64 and $14.36 \mathrm{MHz}$ the events are rarely observed. In spring, the occurrence strongly depends on frequency, peaking at $10.39 \mathrm{MHz}$. Type 4 events are also a springtime phenomenon, being observed on over $30 \%$ of nights for 10.39 and $11.12 \mathrm{MHz}$, but rarely at other frequencies.

At frequencies of $8.01 \mathrm{MHz}$ and below, Type 1 propagation events become more frequent as $\mathrm{Kp}$ increases, while for frequencies higher than this the percentage of nights on which this type of propagation is observed is roughly independent of $\mathrm{Kp}$ (although there is

Type 2, $8.01 \mathrm{MHz}, 2007 / 04 / 18,21: 17$ UT, Kp=2.5

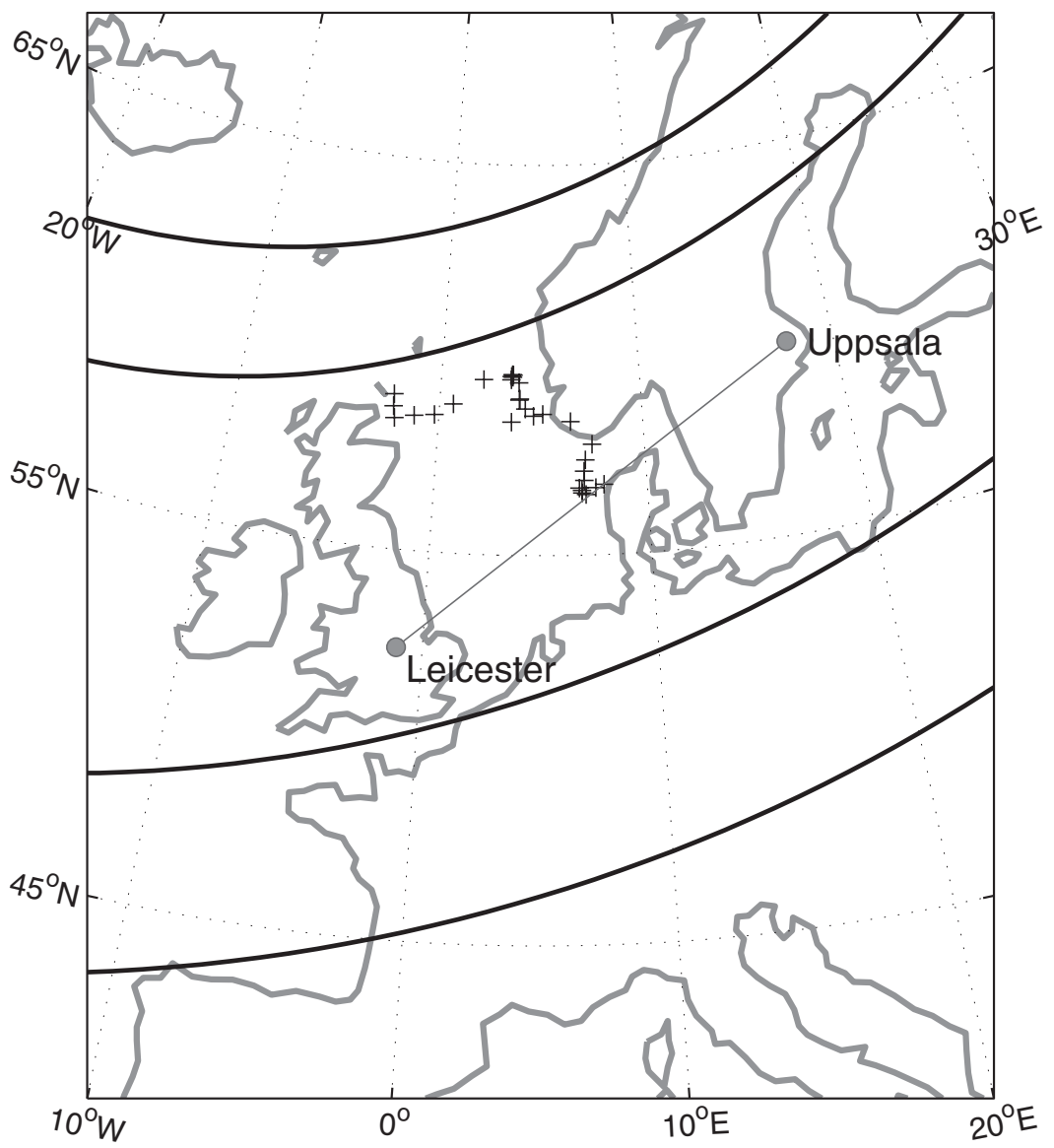

Fig. 4. Map showing the inferred reflection point of an $8.01 \mathrm{MHz}$ signal on 18 April 2007, 2030UT to 19 April, 0000 UT. 
ISL ELECTRON DENSITY (Ne)
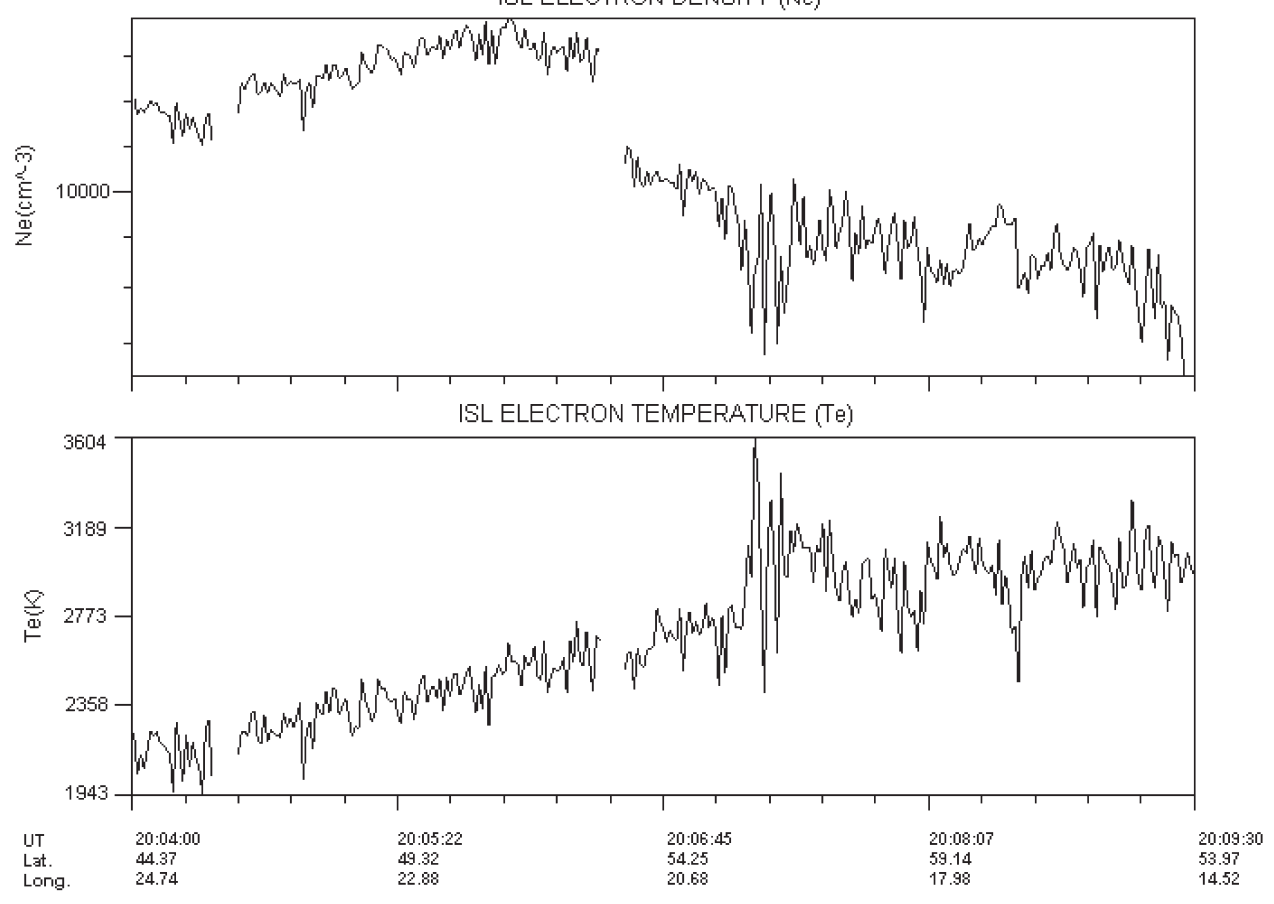

Fig. 5. The electron density and temperature measured on board of DEMETER satellite on 18 April 2007.

some suggestion of a slight decrease in occurrence with increasing Kp). For Type 2 propagation, there is a clear decrease in the occurrence of observations with increasing $\mathrm{Kp}$ for all frequencies except $4.64 \mathrm{MHz}$, where the opposite is the case. Type 4 propagation is more commonly observed at the middle range of frequencies (8.01-11.12 MHz), and becomes more frequent with increasing Kp.

\subsection{Comparison of satellite measurements with HF measurements}

The mechanism by which Type 1 off great circle path propagation occurs has been investigated through simulation (Siddle et al., 2004b). However, the modelling has not yet been able to explain why the deviations of dif- ferent types occur on one day but not on otherwise very similar days. In previous work, the parameters describing electron density irregularities embedded in the background ionosphere used in simulation have not been well defined. In this paper, the HF measurements are examined in conjunction with satellite observations of the electron density structure. Some caution must be exercised in comparing the HF and satellite measurements since the satellite altitude is about $700 \mathrm{~km}$, while the HF propagation is most strongly affected by the ionosphere at heights of about $200-400 \mathrm{~km}$. Since the electron density distribution in the topside ionosphere is the near-Earth signature of the magnetospheric plasmapause, it may be expected that the structure of the irregularities due to precipitations will be well correlated at different altitudes, while the behaviour of the instabilities 
inside the trough region will depend on height. For reasons of space, only a single example of Type 2 off great circle propagation from 18 April 2007 will be presented here.

Based on the measured angles of arrival and the time of flight of the HF signal (fig. 2), and assuming a single, mirror-like reflection (see Siddle et al., 2004b), the reflection point (fig. 4) moves steadily north of the great circle path reaching a point close to the poleward wall of the trough before the signal is no longer received. It is evident from Figure 4 that the reflection points of the HF signal in this event are located inside the trough. The DEMETER satellite data (fig. 5) indicates that, as well as the expected reduction in electron density, there are strong filamentary electron density structures (i.e. irregularities) inside the main ionospheric trough at this time, and we suggest that scattering from these irregularities is the main mechanism responsible for formation of Type 2 off great circle propagation.

\section{Ionospheric model for ray-tracing}

Zaalov et al. (2003; 2005) have developed a unique ray-tracing model that accurately reproduces many of the features observed in the experimental measurements referred to earlier to a level well beyond that which we originally anticipated would be possible. A major outcome of these ray-tracing simulations is that paths other than those that have been the subject of experimental investigation can readily be assessed.

The simulations make use of a numerical ray tracing code (Jones and Stephenson, 1975) to estimate the ray paths through a model ionosphere comprising two Chapman layers, the main parameters of which (critical frequency, critical height, vertical scale height of each layer) are based on values obtained from the International Reference Ionosphere (IRI) (Bilitza, 1990). The most important causes of off-great circle propagation in the polar cap are the presence of convecting patches or sun-aligned arcs of enhanced ionisation. Patches are formed in the dayside auroral oval and generally convect in an anti-sunward direction across the polar cap into the nightside auroral oval, whereas arcs occur under different geomagnetic conditions and drift in a duskwards direction. Localised, time varying, perturbations in the electron density are then applied to the background model to represent the convecting patches and arcs of enhanced electron density.

Sun aligned arcs (Carlson et al., 1984): the shape of each sun-aligned arc is defined within the model by a small number of three-dimensional Gaussian perturbations in electron density of different spatial scales (altitude, longitude and latitude) randomly distributed near to the centre of the arc. Several Gaussian perturbations were combined in defining the shape of each modelled arc in order to prevent the shapes of the arcs being too stylised. For all arcs away from close proximity to the dawn or dusk auroral oval, the plasma strands are elongated for several hundreds or thousands of kilometres with a latitudinal scale which is significantly larger than the longitudinal scale. Evolution of the structures relative to the propagation path is determined by the rotation of the Earth beneath the arcs and by movement of the arcs in the dawn-dusk direction.

Convecting patches (Weber et al., 1984; Buchau et al., 1983): the temporal evolution of the patches relative to the propagation path is simulated by means of a convection flow scheme coupled with the rotation of the Earth beneath the convection pattern, the precise form of which depends upon the components of the IMF. The intensity and spatial scales of the patches can also be varied with simulation time. In practice, the shape, size and number of patches in the convection flow area depends upon many geophysical parameters, not only upon the instantaneous values but also upon their history. By using up to four vortices based on the modelled convection flow patterns associated with the various IMF orientations many realistic situations may be simulated.

Mid-latitude trough: the Halcrow and Nisbet model (1977) was used in the simulations as a basis for the position of the trough walls. In order to add smaller-scale structure to the wall, the following modifications were performed: (a) The latitude of the walls was perturbed by two-scaled random functions of longitude, and 

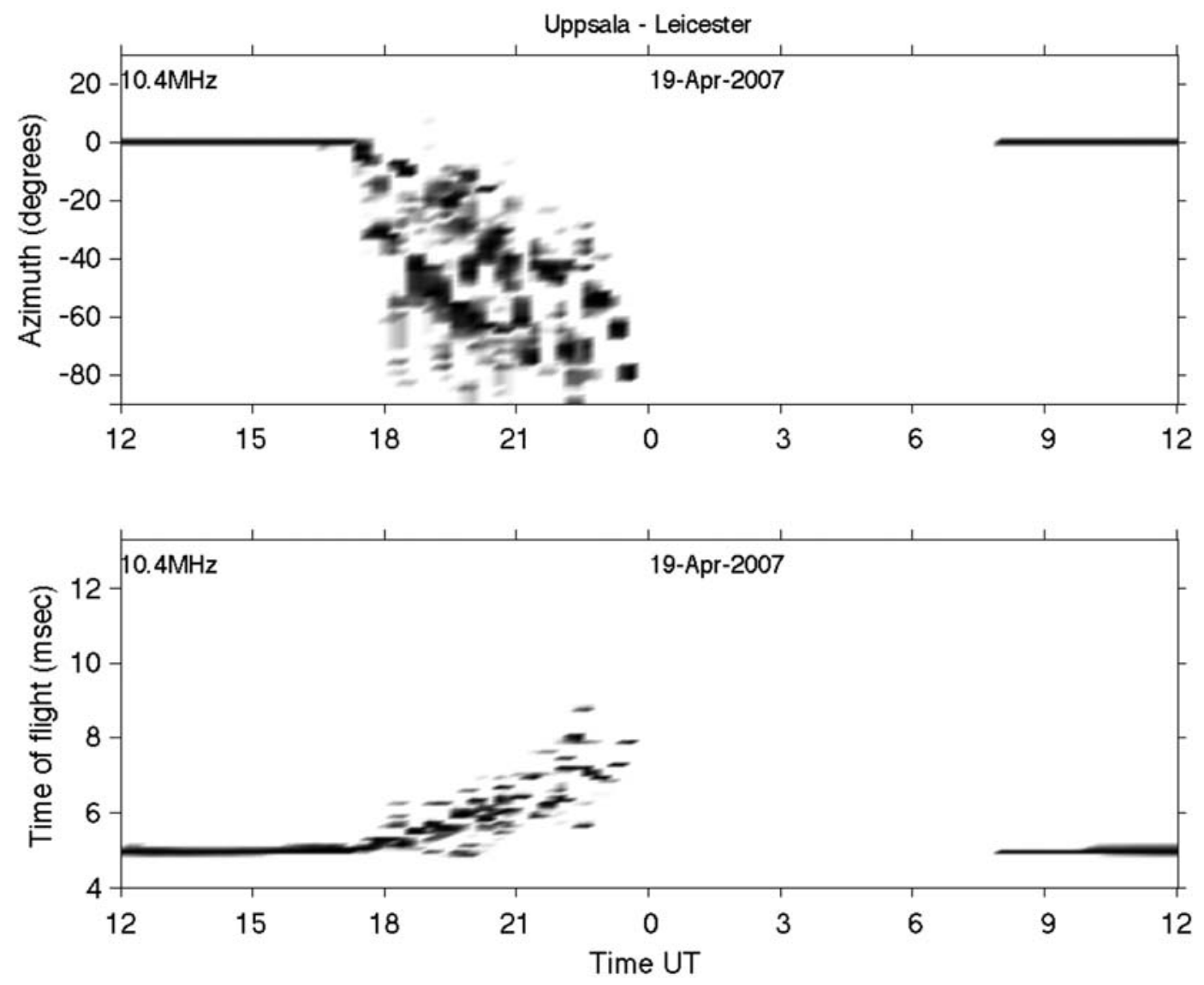

Fig. 6. Simulated time history of the azimuth of arrival and time of flight of a $10.4 \mathrm{MHz}$ signal propagating along Uppsala to Leicester path between noon 18 April and noon 19 April 2007. Azimuth deviation - top panel, time of flight - bottom panel.

(b) a landscape of patches elongated in the direction of the trough were added to each wall. Initially, no perturbations were added to the floor of the trough. The depletion of the trough maximum was set according to $\mathrm{Kp}$, typically, $30 \%$ for $\mathrm{Kp}=2-3$ and $60 \%$ for $\mathrm{Kp}=6$.

Particle precipitation: the auroral oval is an enhancement of electron density caused by particle precipitation in the $E$-region and above. As a function of distance along (near-vertical) field lines, the density enhancement was modelled as starting $100 \mathrm{~km}$ from the ground, having one or more peaks of about $10^{13}$ electrons $/ \mathrm{m}^{3}$ around $110 \mathrm{~km}$, and then decaying slowly toward 200 km (Bates and Hunsucker, 1974). Small scale electron density enhancements can also be added to the model.

The model is able to reflect the day-to-day variation of received HF signals. See, for example, the time history of the azimuth of arrival and time of flight of a $10.4 \mathrm{MHz}$ signal propagating along Uppsala to Leicester path on 18-19 April 2007 given in fig. 2 and the simulation results in fig. 6 . 


\section{Area coverage simulations}

The area coverage to be expected from a transmitter at a given location can be estimated by ray-tracing through the model ionospheres described in Section 2. A large number of rays launched in an azimuth/elevation grid from the transmitter are traced through the model ionosphere, and the signal strength at the receiver estimated by determining the ray-density in the area around the receive antenna. For the example simulations presented in this case, the dynamic range shown in the figures has been restricted to $20 \mathrm{~dB}$ in order to highlight the modal structure of the signal.
An example outcome of this process is illustrated in figs. 7 and 8 . The first of these figures shows a modelled electron density distribution at a height of $200 \mathrm{~km}$ and a time of 0230 UT (the dayside ionosphere is positioned in this figure around the bottom left quadrant). Patches of enhanced ionisation have been randomly positioned within the model ionosphere, as described previously.

The outcome of the ray-tracing process is illustrated in fig. 8 for a frequency of $10.4 \mathrm{MHz}$ for transmitters located at Iqaluit and Troms $\varnothing$. The upper frames indicate the expected area coverage when the presence of the patches is ignored, and the lower frames for when the

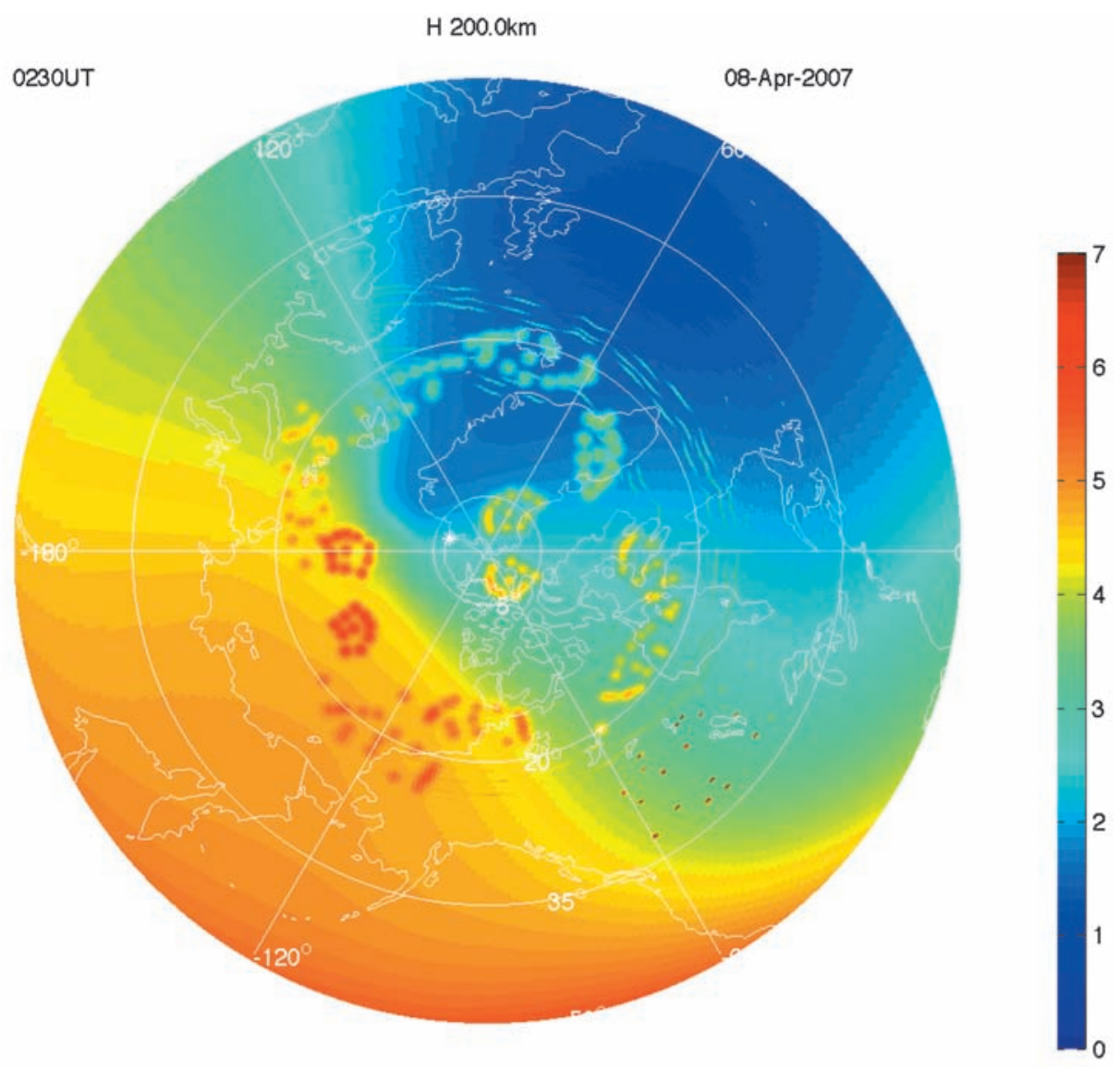

Fig. 7. Example electron density distribution over the high latitude region. The dayside ionosphere is around the lower left hand quadrant. Patches of enhanced electron density are also included. 


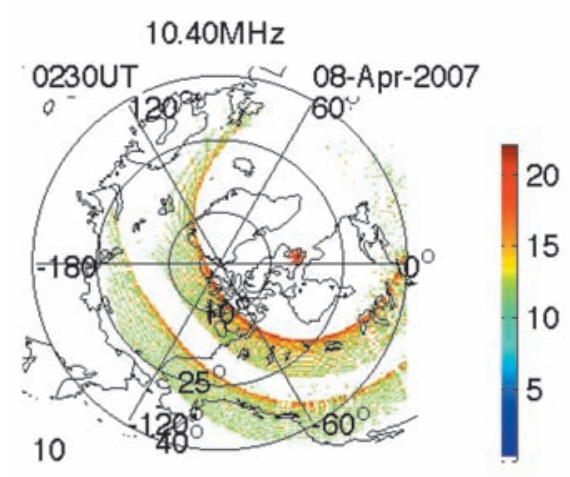

10.40MHz

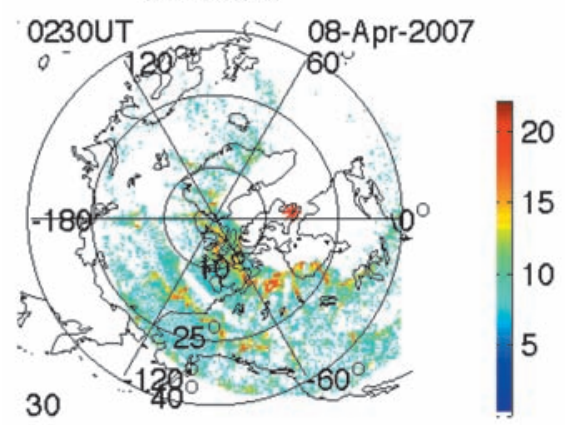

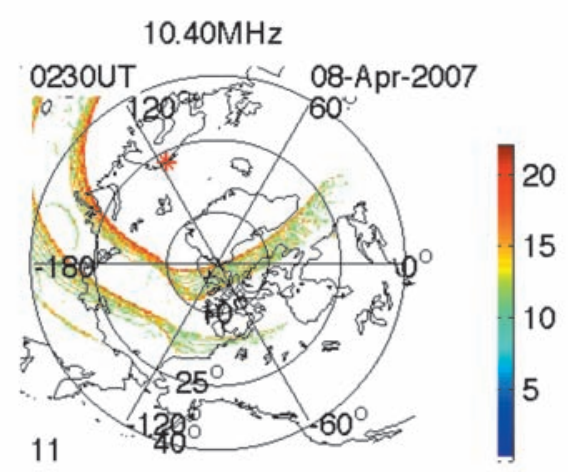

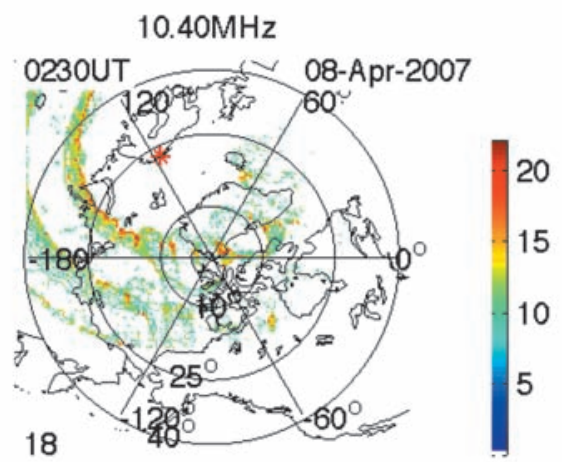

Fig. 8. Calculated signal strength variations for a $10.4 \mathrm{MHz}$ transmitters located at Iqaluit (left frames) and Troms $\varnothing$ (right frames) covering the high latitude region using the modelled ionosphere of fig. 7. The upper frames are without the presence of polar patches, and the lower frames are with the presence of the patches.

patches are taken into account. Focussing of the rays at the 1, 2 and 3 hop skip zone ranges is clearly evident in all cases. It is interesting to note that the presence of the patches severely distorts the background pattern on the ground, that coverage is reduced in places but also that coverage is obtained in areas where it was not present without the presence of the patches. This later situation is more evident at higher frequencies, not illustrated here.

In considering the effect of the presence of the patches, it is important to remember that the patch distribution shown is only illustrative and that in reality the patches will be distributed differently, and also that as time progresses the patches will move in accordance with the pre- vailing convection cell pattern (in turn, a function of the geomagnetic conditions).

\section{Inversion of HF radar backscatter ionograms}

HF radars use the refraction by the ionosphere of radio waves emitted by the radar to detect targets up to $3000 \mathrm{~km}$. The distance covered by the radio waves depends on different parameters: the ionospheric characteristics, the transmitted frequency and the elevation angle. In order to optimise the radar frequencies for the geographical area of interest and to localize the targets accurately, knowledge of the ionospheric charac- 
teristics is required in quasi real time. In to acquire the necessary ionospheric information, the radar can be used as an oblique backscatter sounder. For this purpose, an inversion method is needed as the forward problem is strongly non linear. By scanning the radar beam in elevation for a fixed azimuth at one operating frequency, the group path can be measured to obtain a backscatter ionogram (a 3D image of magnitude, elevation angle $\beta$, and group path $P^{\prime}$ ).

The Quasi-Parabolic Segment model (QPS) developed by Dyson and Bennett (1988) has been chosen for the inversion. In this model, each layer of the ionosphere and also the joining segments can be characterized with a QP segment by only three parameters: the critical frequency $\left(f_{c}\right)$, the peak height $\left(h_{m}\right)$ and the semithickness $\left(y_{m}\right)$. Then the group path $P^{\prime}$ and the ground range $D$ can be obtained using analytical propagation equations.

\subsection{Inversion technique}

The purpose is to recover the initial model parameters $\left(f_{c}, h_{m}, y_{m}\right)$ of each layer of the ionosphere from $n$ points of the backscatter ionogram $(n \geq 3)$. With these model parameters the calculation of the ground range, $D$, is possible so the real position of the target can be determined. The data points used are the coordinates of $n$ group paths $\left(P_{\text {meas }}^{\prime} 1, \ldots, P^{\prime}{ }_{\text {meas } n}\right)$ at $n$ fixed elevation angles $\left(\beta_{\text {ref } 1}, \ldots, \beta_{\text {ref } n}\right)$ called of reference for each layer. The method, based on Tarantola (1987) and Landeau et al. (1997), will invert each ionosphere's layer one by one. For each parameter a value is chosen in the parameter space to create a QPS model of the ionosphere and to simulate the elevation-group path curve by using ray tracing. The coordinates of the $n$ group paths simulated corresponding to the $n$ fixed elevation angles are taken $\left(P^{\prime}{ }_{\text {simu }} l, \ldots, P^{\prime}{ }_{\text {simu }}\right)$.

With the coordinates of the $n$ group paths measured and simulated, the a posteriori probability density, $\sigma_{p}$, can be calculated, using the equation:

$$
\sigma_{p}\left(f_{c}, h_{m}, y_{m}\right)=\prod_{i=1}^{n} \frac{1}{1+\left(\frac{P_{\text {simu }}^{\prime}\left(f_{c}, h_{m}, y_{m}\right)-P_{\text {meas } i}^{\prime}}{\delta P_{\text {meas } i}^{\prime}}\right)}
$$

where $\delta P^{\prime}{ }_{\text {meas }}, \ldots, \delta P^{\prime}$ measn represent the variances of the measurement errors over $P^{\prime}$ meas 1 , ..., $P$ ' ${ }_{\text {measn }}$. These variances are presumed to be Cauchy distributed and independent of each other.

The optimal parameters are those for which $\sigma_{p}$ is maximum. To find them, each value of the parameters space must be evaluated. But this procedure is costly in time and the ionosphere is changing with time, sometimes on a time scale smaller than 15 minutes. It is thus necessary to use an optimization algorithm to get a good approximation of the global optimum. Two different optimization algorithms have been tested: the simulated annealing and the genetic algorithm.

Simulated annealing: The simulated annealing algorithm (SA) developed by Kirkpatrick et al. (1983) is based on the manner in which metals recrystallize in the process of annealing. For each step of the SA algorithm a random neighbour of the current solution is considered. If the new solution is better, it is chosen. If it is worse, it can still be chosen with a probability that depends on the difference between the corresponding function values and on a parameter called the temperature $(T)$.

The temperature is gradually decreased during the process. At the beginning the current solution changes almost randomly, but the acceptance of bad solutions decreases as $T$ goes to zero. The allowance for bad solutions saves the method from becoming fixed at local minima.

Genetic algorithm: The second optimization method used is a genetic algorithm developed by Goldberg (1989). Genetic algorithms are based on the mechanics of natural selection and genetics. An initial generation is created where the individuals are binary coded strings. By using selection, crossover and mutation a new generation is created from the old generation. Each generation is better than the previous one, until the optimal solution is found.

\subsection{Validation on synthesized data}

Synthesized data are created from a model of electronic density profile given by predictions of the ionosphere (table I). After calculat- 
Table I. QPS model parameters, initial and estimated, comparison.

\begin{tabular}{ccccc}
\hline \hline Layer & Parameter & Initial value & $\begin{array}{c}\text { Estimated value } \\
\text { with SA }\end{array}$ & $\begin{array}{c}\text { Estimated value } \\
\text { with GA }\end{array}$ \\
\hline E & $\mathrm{f}_{\mathrm{c}}$ & $2.62 \mathrm{MHz}$ & $2.59 \mathrm{MHz}$ & $2.58 \mathrm{MHz}$ \\
$\mathrm{E}$ & $\mathrm{h}_{\mathrm{m}}$ & $105.4 \mathrm{~km}$ & $109.4 \mathrm{~km}$ & $109.24 \mathrm{~km}$ \\
$\mathrm{E}$ & $\mathrm{y}_{\mathrm{m}}$ & $15.1 \mathrm{~km}$ & $19.28 \mathrm{~km}$ & $19.17 \mathrm{~km}$ \\
$\mathrm{~F}$ & $\mathrm{f}_{\mathrm{c}}$ & $7 \mathrm{MHz}$ & $6.99 \mathrm{MHz}$ & $7 \mathrm{MHz}$ \\
$\mathrm{F}$ & $\mathrm{h}_{\mathrm{m}}$ & $261.8 \mathrm{~km}$ & $263.36 \mathrm{~km}$ & $262.9 \mathrm{~km}$ \\
$\mathrm{~F}$ & $\mathrm{y}_{\mathrm{m}}$ & $93.4 \mathrm{~km}$ & $94.75 \mathrm{~km}$ & $93.55 \mathrm{~km}$ \\
\hline
\end{tabular}

ing the group path-elevation angle curve, we add a zero mean Gaussian noise $\left(7.5 \mathrm{~km}\right.$ and $2^{\circ}$ of standard deviation) to simulate a real backscatter ionogram that is used to test the inversion method.

The results of the inversion method are compared to the initial values on fig. 9 and in table I. In fig. 9 the group path-elevation curve obtained by inversion match with the original curve used as data.

The two optimization methods are compared in fig. 10 and in table I. The genetic algorithm converges faster than the simulated annealing (1.72 minutes vs 15 minutes with a PC Intel Dual Core). Furthermore, the estimated parameters provided by the genetic algorithm are closer to the initial values than by using the simulated annealing. In future works, the genetic algorithm will be used.

\subsection{Results on real data}

The inversion method has also been tested on real data using an elevation-scan backscatter ionogram, recorded on 11 June 2007 at 2000 UT. In this particular sounding, only the $F$ layer was present (nighttime's profile). For validation purposes vertical ionograms have been collected by the Ebre ionosonde which was selected because it is located in the great circle of the oblique sounding backscatter beaming.

Figure 11 compares the elevation angle-group path ionograms obtained with the data inversion and the vertical ionosonde inversion. The corresponding electron density profiles presented in fig. 12 show a general agreement of the 2 profiles.

\section{Comparison between observations and prediction techniques}

\subsection{Time of flight measurements and their application to testing predictions methods that approximate to ray tracing}

Accurate predictions of the main parameters characterising the HF ionospheric channel require a detailed knowledge of the ionospheric conditions that only numerical or analytic raytracing techniques can provide. Numerical raytracing models (such as Jones and Stephenson, 1975 and Norman et al., 1994) are very accurate but they have a high computational time. Analytic ray-tracing techniques that enable ray tracing through horizontal gradients along and in the direction of the ray path (Norman and Cannon, 1997; 1999) are computationally less intensive than numerical ray tracing. For this reason their use is particularly advantageous in HF applications such as in the real-time frequency management of OTH (over-the-horizon) radar systems (Coleman, 1998).

Three different predictions methods that approximate ray-tracing techniques were tested: (a) IRI-95 based on the monthly median elec- 


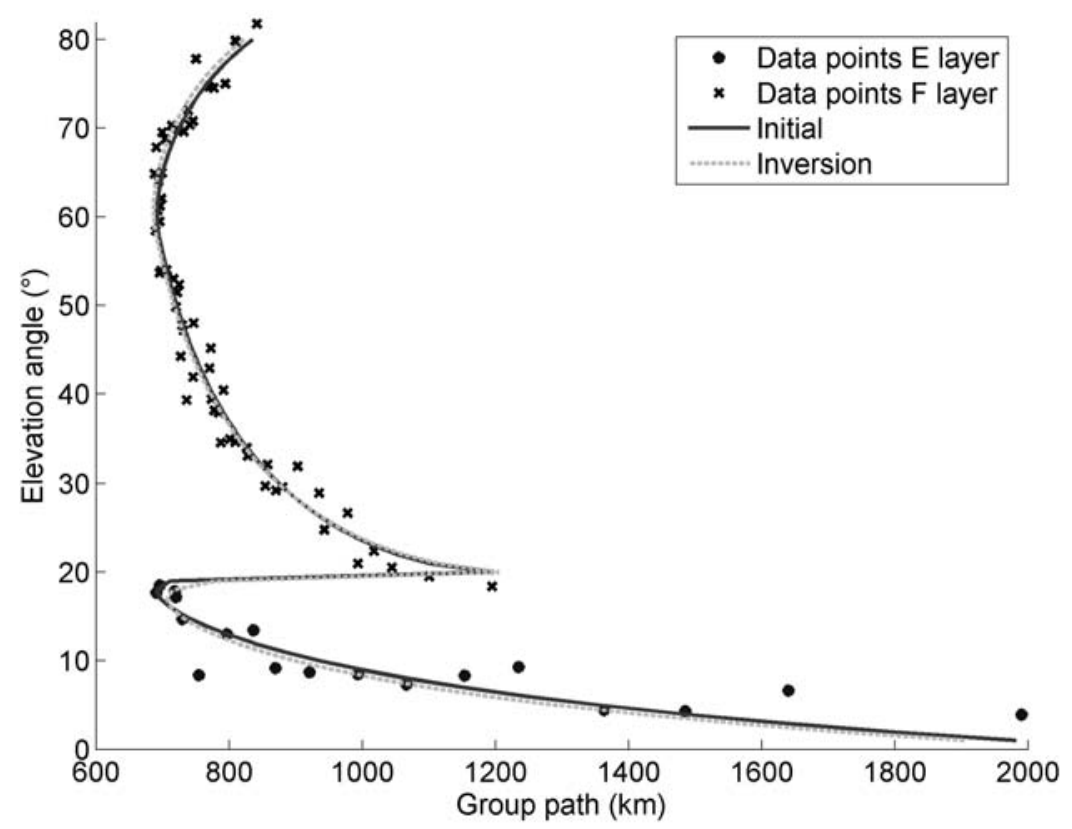

Fig. 9. Backscatter ionogram inversion results.

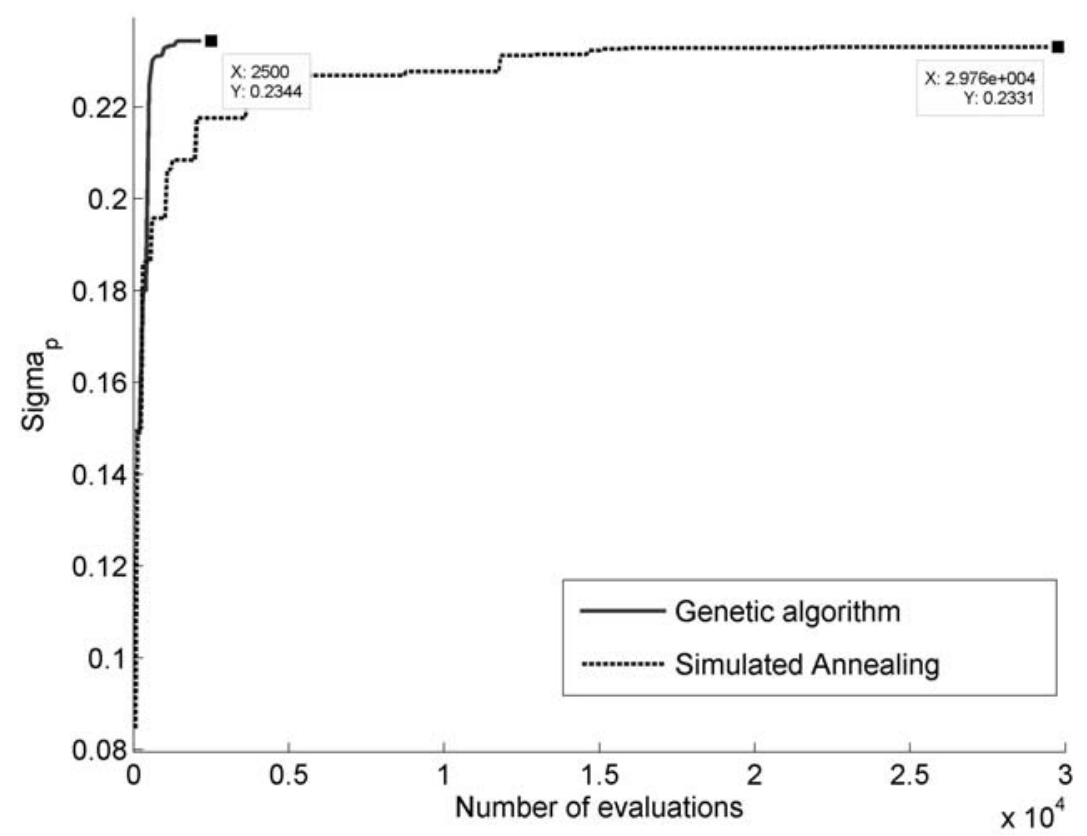

Fig. 10. Comparison of the optimization algorithms speed. 


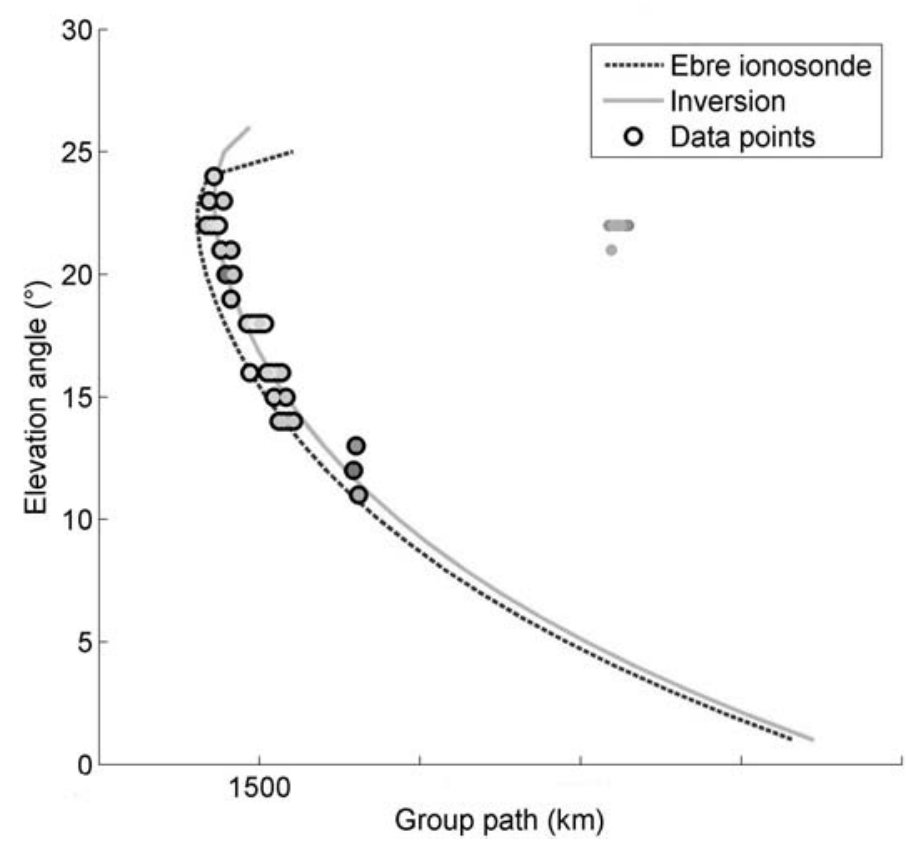

Fig. 11. Elevation angle-group path curves obtained with the inverted parameters and with the ionosonde inversion parameters, and data points used for the inversion at a low operating frequency.

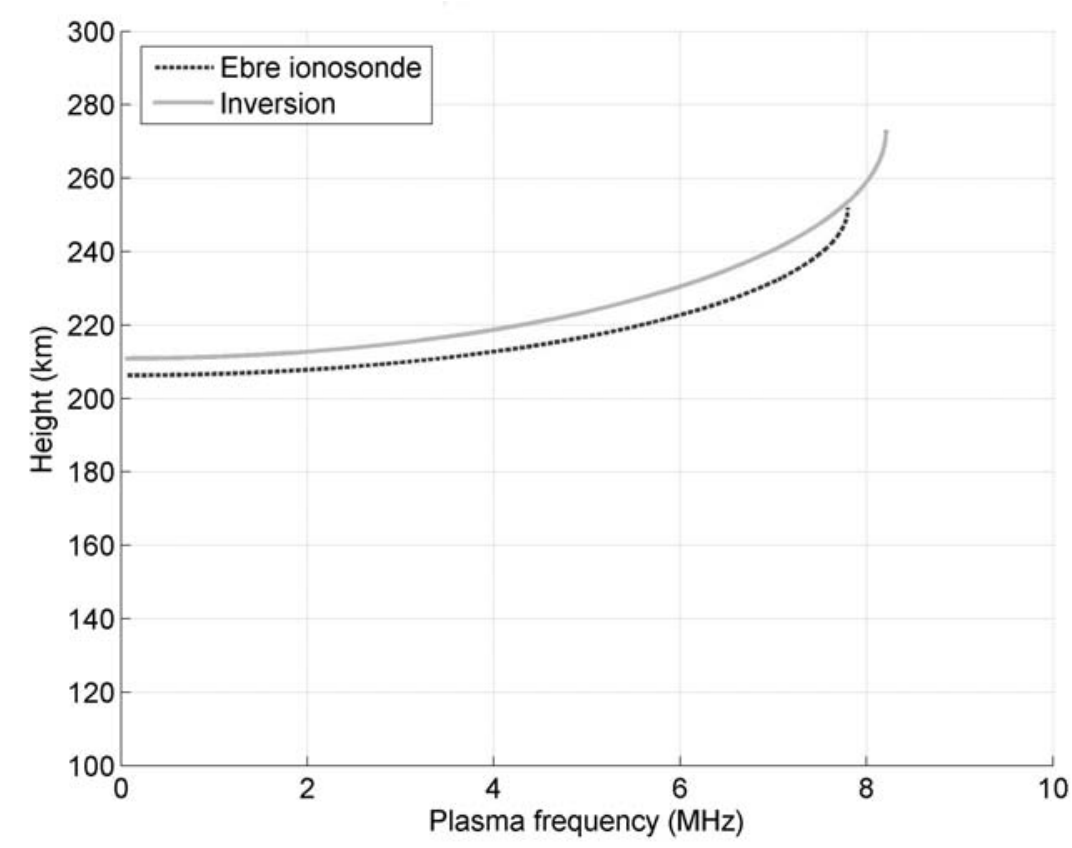

Fig. 12. Electron density profiles obtained with the inverted parameters and with the ionosonde parameters. 
tron density profiles provided by the IRI-95 model (Bilitza, 1990; 2001), (b) SIRM\&BR_D based on the SIRM (Zolesi et al., 1993; 1996) in conjunction with the Bradley-Dudeney model (Bradley and Dudeney, 1973), and (c) ICEPAC based on the Ionospheric Communications Enhanced Profile Analysis and Circuit prediction program (Stewart, undated).

For the IRI-95 and SIRM\&BR_D prediction methods, the monthly median electron density profiles provided by the models have been used to calculate the vertical plasma frequency profiles at the mid-point of the Uppsala Leicester radio link (see Section 1). As the effect of Earth's curvature is important for ground ranges greater than $500 \mathrm{~km}$, the curvature of the Earth and the known ground range $(1411 \mathrm{~km})$ of the radio link have been taken into account for calculating the angle of incidence of the ray at the base of the ionosphere. The values of the angle of incidence have been calculated assuming a very simple geometry based on ionospheric reflections taking place from a simple horizontal mirror at the appropriate height. Subse- quently, the secant law was applied to calculate the oblique transmission frequencies. The length of the oblique ray path, its corresponding time of flight (TOF) and take off angle have been calculated from simple geometry.

The version of ICEPAC used in this study utilizes the monthly median electron density profiles (Haydon and Lucas, 1968) at the midpoint of the radio link derived from CCIR foF 2 and M(3000)F2 coefficients (CCIR, 1966) and, from these, provides predictions of elevation angle, TOF, virtual height, etc. for a given oblique transmission frequency and time of day.

In order to test the validity of these methods under quiet ionospheric conditions, comparisons between the predictions and the TOF median measurements for the one hop propagation modes $1 E$ and $1 F$ were carried out for different frequencies and seasons.

For $1 E$ modes (see table II), IRI-95 and SIRM \&BR_D provide a similar performance, while ICEPAC is in general somewhat better. This is particularly the case when Es is present. The errors for $1 F$ modes (table III) are larger

Table II. The minimum and maximum value of the r.m.s. error of TOF are shown taking into account all the frequencies which arrive at the receiver following the $1 \mathrm{E}$ on great circle propagation modes.

\begin{tabular}{cccc}
\hline \hline 1E propagation mode & $\begin{array}{c}\text { Winter months } \\
\text { r.m.s.min }- \text { r.m.s.max } \\
(\mathrm{ms})\end{array}$ & $\begin{array}{c}\text { Equinoctial months } \\
\text { r.m.s.min }- \text { r.m.s.max } \\
(\mathrm{ms})\end{array}$ & $\begin{array}{c}\text { Summer months } \\
\text { r.m.s.min }- \text { r.m.s.max } \\
(\mathrm{ms})\end{array}$ \\
\hline IRI-95 & $0.038-0.099$ & $0.044-0.085$ & $0.013-0.093$ \\
SIRM\&BR_D & $0.045-0.099$ & $0.043-0.084$ & $0.008-0.072$ \\
ICEPAC & $0.002-0.048$ & $0.022-0.062$ & $0.002-0.082$ \\
\hline
\end{tabular}

Table III. The minimum and maximum value of the r.m.s. error of TOF are shown taking into account all the frequencies which arrive at the receiver following the $1 \mathrm{~F}$ on great circle propagation modes.

\begin{tabular}{cccc}
\hline \hline 1F propagation mode & $\begin{array}{c}\text { Winter months } \\
\text { r.m.S.min }- \text { r.m.s.max } \\
(\mathrm{ms})\end{array}$ & $\begin{array}{c}\text { Equinoctial months } \\
\text { r.m.s.min }- \text { r.m.s.max } \\
(\mathrm{ms})\end{array}$ & $\begin{array}{c}\text { Summer months } \\
\text { r.m.S.min }- \text { r.m.s.max } \\
(\mathrm{ms})\end{array}$ \\
\hline IRI-95 & $0.071-0.325$ & $0.072-0.393$ & $0.111-0.572$ \\
SIRM\&BR_D & $0.097-0.139$ & $0.070-0.254$ & $0.108-0.340$ \\
ICEPAC & $0.025-0.325$ & $0.093-0.396$ & $0.095-0.432$ \\
\hline
\end{tabular}


than for $1 E$, and the performance is similar for all three methods, although ICEPAC can produce significantly better results in winter.

Further details of this aspect of the investigation can be found in Pietrella et al. (2009).

\subsection{Comparison of oblique sounding measurements and VOACAP predictions on a mid-latitude path between Cyprus and the UK}

Signals from FMCW sounders located in Cyprus were received in Leicester (a path length $\sim 3340 \mathrm{~km}$ ) from 1 February 2008 to 13 July 2008 . The monthly median MUF as a function of time of day is presented in fig. 13. Predictions of the MUF made using VOACAP (version 05.0119W) are also presented in fig. 13. VOACAP has been run using a minimum take-off angle of $0.1^{\circ}$, pre- dicted smoothed sunspot numbers ranging from 7 in February to 11 in July (NGDC, 2008), and with the sporadic E model switched off. Although the observations generally have a similar form to the predictions, there are some discrepancies. For example, the predicted median MUF at 0700-0800 UT in February is much higher than the observed value (the largest daily value in the month is 21.9 $\mathrm{MHz}$ at $0700 \mathrm{UT}$ and $23.5 \mathrm{MHz}$ at $0800 \mathrm{UT}$ ), in June the characteristic reduction in MUF at noon is not observed, whilst in July, the observed MUF is higher than the predicted value at all times. In June and July the discrepancy results from the presence of sporadic-E layers with high (on occasions $>30 \mathrm{MHz}$ ) peak frequencies. The predicted MUF(Es) values (obtained using VOACAP method 11, with a FPROB multiplier of 1.0 for Es) are closer to those observed in the morning and early afternoon, but significantly lower than the observations in the evening.

Table IV. Modem availabilities with DST=0

\begin{tabular}{ccccccc}
\hline \hline & $2400 \mathrm{bps}$ & $1200 \mathrm{bps}$ & $600 \mathrm{bps}$ & $300 \mathrm{bps}$ & $150 \mathrm{bps}$ & $75 \mathrm{bps}$ \\
\hline $4 \mathrm{MHz}$ & 0 & 0 & 0.004 & 0.983 & 0.974 & 1 \\
$6 \mathrm{MHz}$ & 0 & 0.026 & 0.245 & 0.891 & 0.869 & 0.983 \\
$10 \mathrm{MHz}$ & 0.288 & 0.472 & 0.576 & 0.978 & 0.978 & 0.991 \\
$11 \mathrm{MHz}$ & 0.179 & 0.424 & 0.533 & 0.987 & 0.974 & 1 \\
$14 \mathrm{MHz}$ & 0.122 & 0.258 & 0.380 & 0.987 & 0.978 & 0.996 \\
$18 \mathrm{MHz}$ & 0.153 & 0.183 & 0.253 & 1 & 0.991 & 1 \\
\hline
\end{tabular}

Table V. Modem availabilities with DST=-050

\begin{tabular}{ccccccc}
\hline \hline & $2400 \mathrm{bps}$ & $1200 \mathrm{bps}$ & $600 \mathrm{bps}$ & $300 \mathrm{bps}$ & $150 \mathrm{bps}$ & $75 \mathrm{bps}$ \\
\hline $4 \mathrm{MHz}$ & 0 & 0 & 0.04 & 1 & 0.96 & 1 \\
$6 \mathrm{MHz}$ & 0 & 0 & 0.12 & 0.96 & 0.92 & 1 \\
$10 \mathrm{MHz}$ & 0.32 & 0.4 & 0.56 & 1 & 0.96 & 1 \\
$11 \mathrm{MHz}$ & 0.2 & 0.4 & 0.56 & 1 & 0.92 & 11 \\
$14 \mathrm{MHz}$ & 0.08 & 0.2 & 0.28 & 1 & 0.92 & 1 \\
$18 \mathrm{MHz}$ & 0.16 & 0.2 & 0.2 & 1 & 0.96 & 1 \\
\hline
\end{tabular}



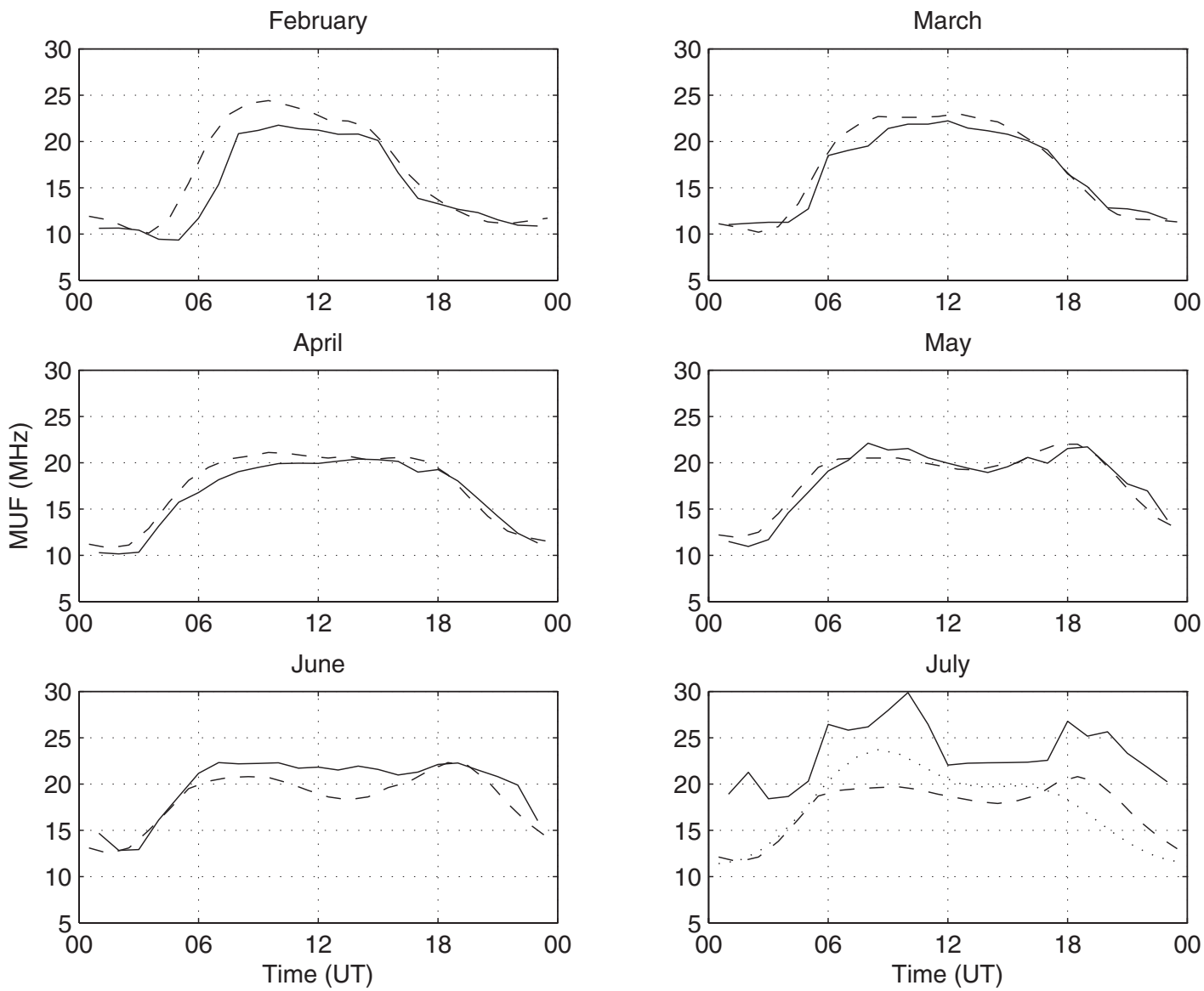

Fig. 13. Monthly median MUF on a path Cyprus-Leicester for February to July 2008. The observations are plotted as a solid line, while the dashed line represents predicted values from VOACAP (the predicted MUF(Es) is plotted as a dotted line in the July panel). All month-hours had at least 26 observations with the exception of July, which only had 13 for all hours.

\section{Assessment of $\mathrm{HF}$ channel availability under ionospherically disturbed conditions}

Various workers have conducted investigations on the signalling characteristics of $\mathrm{HF}$ channels, and on the influence of the channel scattering characteristics on data communications capabilities. For example, Jodalen et al. (2001) reported on a comparison between modem characterisations and channel measurements from the Doppler and Multipath Sound- ing Network (DAMSON) (Cannon et al., 2000). This system characterised narrow-band channels by measuring their SNR, Doppler spread, and delay spread parameters. Measurements of these characteristics may then be applied to three-dimensional performance surfaces to assess signalling capability for various types of modem.

For the path from Sweden to the UK discussed earlier in this paper, Warrington and Stocker (2003) previously reported the variation in delay and Doppler spreading observed 


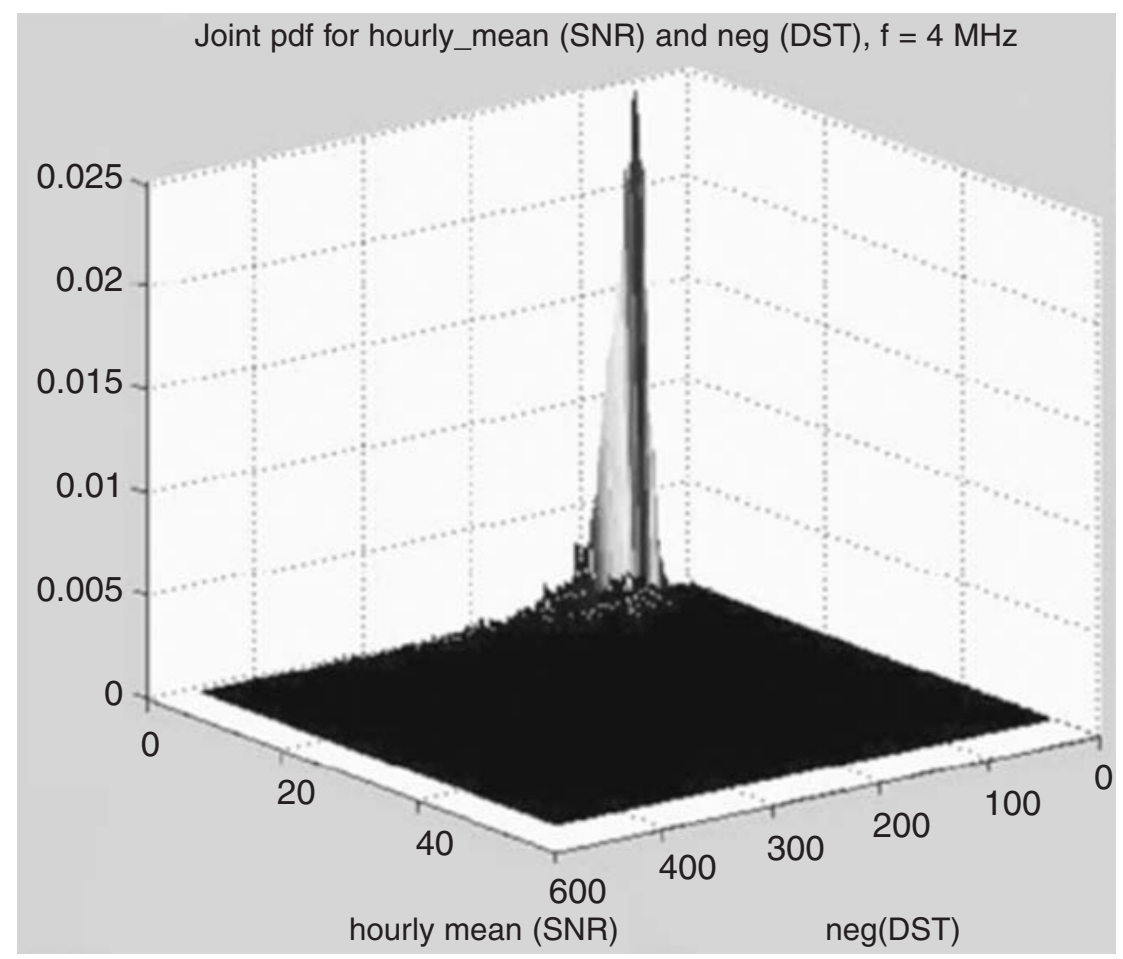

Fig. 14. Joint PDF for hourly mean of SNR and negative of DST, $4 \mathrm{MHz}$ (Sari, 2006).

as a function of season and time of day. This previous analysis did not consider variations with ionospheric disturbance, a topic that is addressed here. Joint probability density functions (PDFs) of SNR, Doppler spread, and effective multipath spread versus the Disturbance Storm Type (DST) index (see, for example fig. 14) were produced for measurements made over the path from Uppsala, Sweden $\left(59.92^{\circ} \mathrm{N} ; 17.63^{\circ}\right.$ E) and Leicester UK $\left(52.63^{\circ} \mathrm{N} ; 1.08^{\circ} \mathrm{W}\right)$ in 2001. It has been demonstrated by Sari (2006) by determining the conditional PDFs and by using Bayes' Theorem, that there were dependencies between DST and the above mentioned signal parameters.

As examples of modem characterizations, various military standards were considered. In these standards, HF modem performances are specified in terms of effective multipath spread, Doppler spread, SNR, bit error rate, modulation type, and data conversion (long-short interleaver). Modem availability was quantified as a fraction of the time that the modem would function satisfactorily (the availability of a modem can be estimated by determining the difference between the measured SNR and the SNR required to give an acceptable BER for a given delay and Doppler spread - a positive SNR difference indicates that the modem would operate satisfactorily (see fig. 15)). Tables IV and V show the probability of modem availability for different data rates and frequencies according to requirements defined in STANAG 4538.

\section{Concluding remarks}

Various propagation related topics of direct relevance to the planning and operation of HF radio systems have been investigated during the 


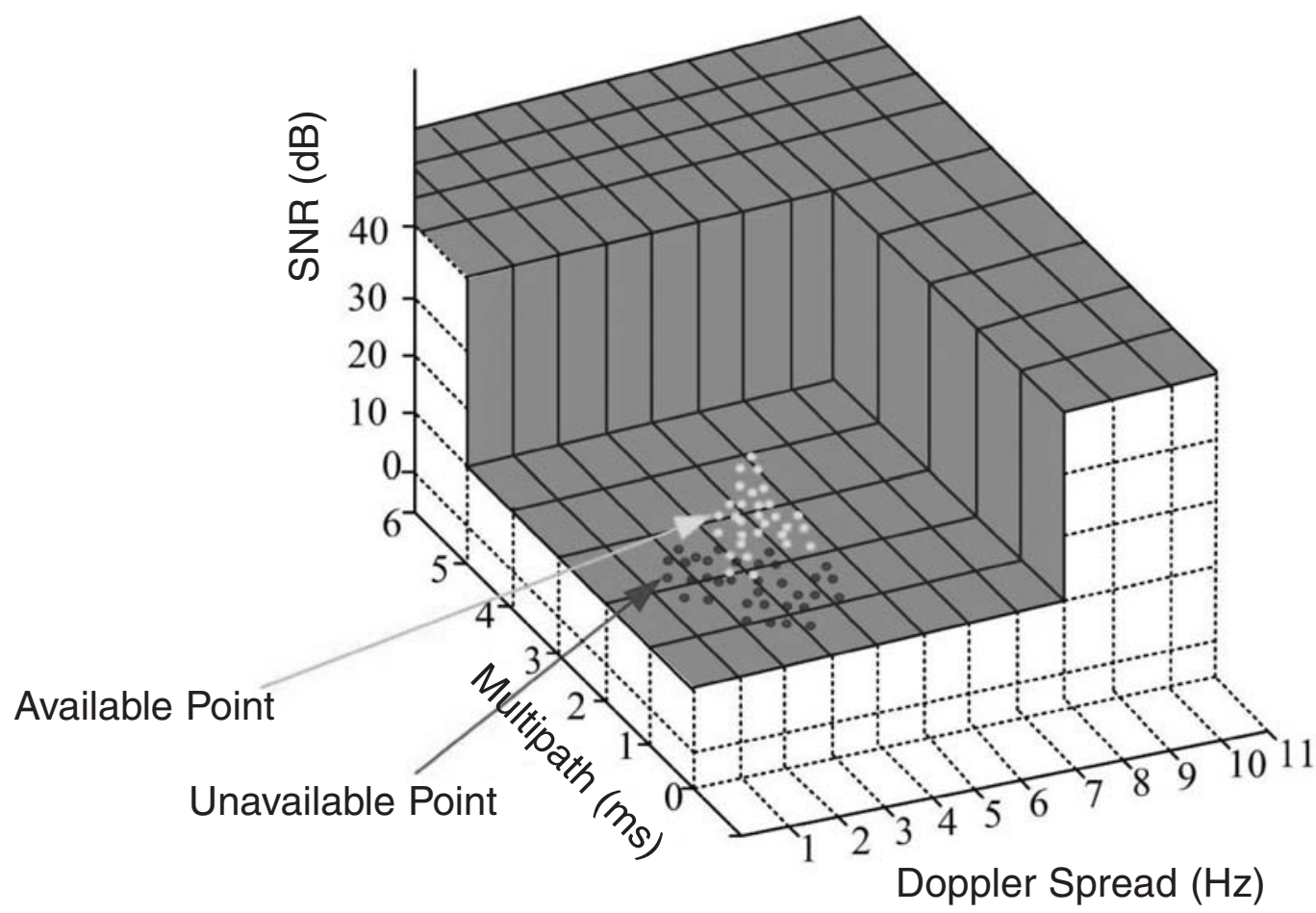

Fig. 15. Approximated availability surface according to STANAG 4538 (NATO, 2000).

COST 296 Action, outline details of which are presented in this paper. For mid-latitude paths, these investigations have included comparisons between predicted channel MUFs for a path from Cyprus to the UK with predicted values obtained using VOACAP. Significant progress has been made in relation to the operation of HF over the horizon radars. Such systems require detailed knowledge of the ionospheric electron density profile. In the work presented here, the radar is operated as a backscatter sounder for a period to measure the backscatter characteristics as a function of frequency and elevation angle. These measurements are then input to a new inversion technique to obtain the required electron density profile.

The results presented in the paper illustrate the importance of understanding and taking into account the presence of various structural features in the northerly ionosphere, i.e. the electron depletion and irregularities associated with the sub-auroral trough, patches and arcs of enhanced electron density within the polar cap, and irregularities within the auroral zone when planning and operating HF radio links. These features result in radiowaves propagating over paths well displaced from the great circle direction and have clear relevance in the operation of HF radiolocation (HF-DF) systems where deviations from the great circle path may result in significant (sometimes inter-continental) triangulation errors. A full understanding of the prevailing propagation mechanisms will enable appropriate selection of receiver sites to be made in order to optimise the positional accuracy. However, the impact of these propagation effects is much wider than this particular application, extending to almost any HF communications system where the signal impacts on the ionosphere within the region polewards of the 
sub-auroral trough. This has been illustrated here by employing the northerly ionospheric model to indicate the effect of polar patches on the coverage area of two transmitters located at Arctic sites. Development of this aspect is currently being undertaken with the aim of improving the HF communications forecasts and nowcasts available to the airlines when operating on trans-polar routes (note that over-conservative forecasts of the likelihood of disturbed communications results on flights being rerouted to non-polar routes with consequent increases in flight time and fuel usage). In addition to the directionally related effects referred to above, the channel transfer characteristics are also affected by the presence of the ionospheric structures, in particular increases in delay and Doppler spread are evident. These increased spreads limit the available data throughput available on a particular channel, or alternatively the system availability may be reduced for a particular type of modem. Consideration of this aspect has been given for the trough path.

\section{Acknowledgements}

The authors would like to thank the Swedish Meteorological Institute, Uppsala and the Finnish Meteorological Institute, Helsinki for hosting the transmitter systems. The authors would also like to acknowledge support from the EPSRC under various grants.

\section{REFERENCES}

BATES, H.F. and R.D. HunsuCKER (1974): Quiet and disturbed electron-density profiles in auroral zone ionosphere, Radio Science, 9 (4), 455-467.

BiLITZA, D. (ed.) (1990): International Reference Ionosphere 1990, NSSDC 90-22, (Greenbelt, Maryland, USA).

BilitZA, D. (2001): International Reference Ionosphere 2000, Radio Science, 36 (2), 261-275.

Bradley, P.A. and J.R. Dudeney (1973): A simple model of the vertical distribution of electron concentration in the ionosphere, Journal of Atmospheric and Terrestrial Physics, 35, 2131-2146.

Buchau, J., B.W. Renisch, E.J. Weber and J.G. Moore (1983): Structure and dynamics of the winter polar cap F region, Radio Science, 18, 995-1010.

Carlson, H.C. JR., V.B. Wickwar, E.J. Weber, J. Buchau, J.G. Moore and W. Whiting (1984): Plasma characteristics of polar cap $F$ layer arcs, Geophysi- cal Research Letters, 11, 895-898.

Cannon, P.S., M.J. Angling and N.J. Davies (2000): DAMSON HF Channel Characterisation - A review, $21^{s t}$ Century Military Communications Conference Proceedings, 1 (2), 59-64.

CCIR (1966): Atlas of ionospheric characteristics, Report 340-1, ITU, (Geneva, Switzerland).

Coleman, C.J. (1998): A ray-tracing formulation and its application to some problems in over-the-horizon radar, Radio Science, 33 (4), 1187-1197.

Dyson, P.L. and P.A. BENNETT (1988): A model of vertical distribution of the electron concentration in the ionosphere and its application to oblique propagation studies, Journal of Atmospheric and Terrestrial Physics, 50 (3), 251-262.

GOLDBERG, D.E. (1989): Genetic algorithms in search, optimization and machine learning, edited by AddisonWesley Publishing Company.

Halcrow, B.W. and J.S. NisBet (1977): A model of the $F 2$ peak electron densities in the main trough region of the ionosphere, Radio Science, 12, 815-820.

Haydon, G.W. and D.L. LuCAS (1968): Predicting ionosphere electron density profiles, Radio Science, 3 (13), 111-119.

ITU (INTERNATIONAL TELECOMMUNICATIONS UNION) (1997): Standardized procedure for comparing predicted and observed HF sky-wave signal intensities and the presentation of such comparisons, ITU-R Recommendation P1148-1.

Jodalen, V., T. Bergsvik, P.S. CANNON and P.C. ARthur (2001): Performance of HF modems on high-latitude paths using multiple frequencies, Radio Science, 36 (6), 1687-1698.

JonES, R.M. and J.J. STEPHENSON (1975): A Versatile Three-Dimensional Ray Tracing Computer Program for Radio Waves in the Ionosphere, Office of Telecommunications, OT 75-76, (U.S Department of Commerce, Washington, USA).

KirKPATRICK, S., C.D. GelatT, Jr. and M.P. VeCChi (1983): Optimisation by Simulated Annealing, Science, 220 (4598), 671-680.

Landeau, T., F. Gauthier and N. Ruelle (1997): Further improvements to the inversion of elevation-scan backscatter sounding data, Journal of Atmospheric and Solar-Terrestrial Physics, 59 (1), 125-138.

NATO (2000): STANAG 4538 Technical Standards for an Automatic Radio Control System (ARCS) for HF communication links, (NATO Military Agency for Standardisation).

NGDC (2008): National Geophysical Data Centre, Boulder, Colorado USA, ftp://ftp.ngdc.noaa.gov/STP/SOLAR_DATA/SUNSPOT_NUMBERS/2008

Norman, R.J., J.A. BENNETT, P.L. DYSON and J.A. NGUYEN (1994): HIRT: homing-in ray tracing program, research report, School of Physics., (La Trobe University, Bundoora, Victoria, Australia).

Norman, R.J. and P.S. CANNON (1997): A two-dimensional analytic ray tracing technique accommodating horizontal gradients, Radio Science, 32 (2), 387-396.

NORMAN, R.J. and P.S. CANNON (1999): An evaluation of a new two-dimensional analytic ionospheric ray-tracing technique: Segmented method for analytic ray tracing (SMART), Radio Science, 34 (2), 489-499. 
Pietrella, M., E.M. Warrington, A.J. Stocker and C. BIANCHI (2009): Time of flight measurements over a radio-link from Uppsala to Bruntingthorpe and their application to testing predictions methods that approximate the ray tracing technique, Advances in Space Research, doi:10.1016/j.asr.2008.09.038.

RogERS, N.C., E.M. WARRINGTON and T.B. JONES (1997): Large HF bearing errors for propagation paths tangential to the auroral oval, IEE Proceedings on $\mathrm{Mi}$ crowaves, Antennas and Propagation, 144 (2), 91-96.

SARI, M.O. (2006): A New Approach For The Assessment of HF Channel Availability Under Ionospheric Disturbances, MS Thesis, Electrical and Electronics Eng., (Middle East Technical Univ., Ankara, Turkey).

Siddle, D.R., A.J. Stocker and E.M. WARRington (2004a): The time-of-flight and direction of arrival of $\mathrm{HF}$ radio signals received over a path along the mid-latitude trough: observations, Radio Science, 39 (4), RS4008, doi:10.1029/2004RS003049.

Siddle, D.R., A.J. Stocker and E.M. Warrington (2004b): The time-of-flight and direction of arrival of HF radio signals received over a path along the mid-latitude trough: theoretical considerations, Radio Science, 39 (4), RS4009, doi:10.1029/2004RS003052.

Stocker, A.J., E.M. WARrington and T.B. Jones (2003): A comparison of observed and modelled deviations from the great circle direction for a $4490 \mathrm{~km}$ HF propagation path along the mid-latitude ionospheric trough, Radio Science, 38 (3), 1045, doi:10.1029/2002RS002781.

Stocker, A.J., N.Y. ZaAlov, E.M. WARRINGTON and D.R. SIDDLE (2009): Observations of HF propagation on a path aligned along the mid-latitude trough, $A d$ vances in Space Research, 44 (1), 64-71, doi:10.1016/j.asr.2009.03.07.
STEWART, F.G (undated): ICEPAC (Ionospheric Communications Enhanced Profile Analysis and Circuit analysis program) Technical Manual, (available for download at http://www.greg-hand.com/manuals/icepac_tech_manual.pdf)

TARANTOLA, A. (1987): Inverse Problem Theory, Methods for data fitting and model parameter estimation, edited by Elsevier Science.

WARRINGTON, E.M. and A.J. Stocker (2003): Measurements of the Doppler and multipath spread of HF signals received over a path oriented along the mid-latitude trough, Radio Science, 38 (5), 1080, doi: $10.1029 / 2002 R S 002815$.

Weber, E.J., J. Buchau, J.G. Moore, J.R. Sharber, J.D. Livingston, J.D. WinNingham and B.W. ReINISCH (1984): $F$ layer ionization patches in the polar cap, Journal of Geophysical Research, 89, 1683-1694.

ZAALOV, N.Y., E.M. WARRINGTON and A.J. STOCKER (2003): The simulation of off-great circle HF propagation effects due to the presence of patches and arcs of enhanced electron density within the polar cap ionosphere, Radio Science, 38 (3), 1052, doi:10.1029/2002RS002798.

ZaAlov, N.Y., E.M. Warrington and A.J. Stocker (2005): A ray-tracing model to account for off-great circle HF propagation over northerly paths, Radio Science, 40 (4), RS4006, doi:10.1029/2004RS003183.

Zolesi, B., L.R. CANDER and G. De Franceschi (1993): Simplified ionospheric regional model for telecommunication application, Radio Science, 28 (4), 603-612.

Zolesi, B., L.R. CANDER and G. De Franceschi (1996): On the potential applicability of the simplified ionospheric regional model to different mid-latitude areas, Radio Science, 31 (3), 547-552. 